\title{
Detecção do vírus da diarreia viral bovina em carrapatos Rhipicephalus (Boophilus) microplus alimentados em bovino persistentemente infectado*
}

\author{
Detection of bovine viral diarrhea virus in Rhipicephalus (Boophilus) microplus ticks fed on \\ persistently infected cattle
}

\section{Laura Lopes de Almeida', Fernanda Simone Marks', José Reck Junior², Adriana da Silva Santos ${ }^{3}$, Danilo Carloto Gomes ${ }^{3}$, Itabajara da Silva Vaz Junior ${ }^{4}$, David Driemeier ${ }^{3}$ \& CláudioWageck Canal'}

\begin{abstract}
Background: Bovine viral diarrhea virus (BVDV) is one of the main agents that cause economical losses in cattle worldwide. Congenitally infected calves that are born persistently infected (PI) to BVDV are the main sources of infection to susceptible cattle. Direct contact is the most important form of transmission, but indirect contact can also spread BVDV, not only inside herds, but also between them. Transmission of BVDV by haematophagous insects has been proven experimentally, but the role of ticks in the transmission of BVDV has never been investigated. Ticks can heavily infest cattle raised in tropical areas and Rhipicephalus (Boophilus) microplus is the most important among them. The present experiment was carried out to investigate the role of R. microplus ticks in the transmission of BVDV, experimentally infecting PI calf with ticks.

Material, Methods and Results: Three calves were used in the experiment: one PI calf was identified from a natural outbreak; a second animal was infested with the progeny of a tick fed on the PI calf and the third was kept as a negative control, infested with negative ticks. Viral RNA investigation was performed by reverse transcription followed by polymerase chain reaction (RT-PCR) from the sera of the calves and from ticks (adult females, eggs and larvae that were the progeny of the experimentally contaminated adult females and from the control animal). BVDV RNA was detected in tick adult females fed on the PI calf, but not in the control animal. Experimental infestation of a second cattle with larvae derived from adult females infected with BVDV was not able to produce infection. These data suggest that the virus is able to pass to ticks during feeding on the infected PI animal, but that there is no transmission by transovarial route, as viral RNA was not detected in eggs and larvae from adult females infected with BVDV.

Discussion: Bovine tick is the most important ectoparasite in domestic animals in tropical and subtropical areas. However, its role in transmission of viral agents, particularly BVDV, has not been previously studied. The results of our experiment suggested that adult females of $R$. microplus were not able to transmit the infection to susceptible cattle. However, a macerate of a pool of tick females fed on the PI calf was positive to BVDV. A further validation using a larger number of infested bovines would help to confirm this new finding. $R$. microplus ticks are monoxenic, but it must be considered that the males, different from females, make a non-continual process of blood sucking and may move between bovines to reproduce. Additionally, in conditions of close contact between animals, besides tick males, larvae may change hosts in the early stages of development. These facts do not permit to exclude the risk of direct spread of viral infection in the herd by a same specimen of R. microplus. On the other hand, the presence of virus inside females represents an environmental reservoir of BVDV, which may infect through epithelial abrasions if ingested. These considerations may be reinforced by the fact that in field conditions it has been observed that high animal density favors the fast spread of BVDV in cattle herds. Collectively, these evidences suggest that ticks would represent an additional factor to be allowed for in BVDV transmission. As a conclusion, the present study demonstrates that $R$. microplus can be contaminated with BVDV during blood feeding, strengthening the idea that haematophagous vectors can be involved in the spread of the disease. In spite of the fact that BVDV was not transmited by the progeny of the ticks, it is not possible to discard such form of transmission under natural conditions.
\end{abstract}

Keywords: bovine viral diarrhea virus, Rhipicephalus (Boophilus) microplus, tick, transmission, vector. Descritores: vírus da diarreia viral bovina, Rhipicephalus (Boophilus) microplus, carrapato, transmissão, vetor.

*Suporte financeiro recebido da Coordenação de Aperfeiçoamento de Pessoal de Nível Superior (CAPES), Conselho Nacional de Desenvolvimento Científico e Tecnológico (CNPq), CNPq - Instituto Nacional de Ciência e Tecnologia (INCT) Entomologia Molecular e Fundação de Amparo à Pesquisa do Estado do Rio Grande do Sul (FAPERGS). L.L. Almeida é doutoranda e possui bolsa CAPES. 'Laboratório de Virologia, Faculdade de Veterinária (FaVet), Universidade Federal do Rio Grande do Sul (UFRGS). Avenida Bento Gonçalves nº. 9090, Bairro Agronomia, CEP 91540-000 Porto Alegre, RS, Brasil. ${ }^{2}$ Centro de Biotecnologia, UFRGS. ${ }^{3}$ Setor de Patologia Veterinária, FaVet, UFRGS. ${ }^{4}$ Setor de Imunologia, FAVET e Centro de Biotecnologia, UFRGS. CORRESPONDÊNCIA: C. W. Canal [claudio.canal@ufrgs.br - Fone: +55 (51) 3308 6926]. 


\section{INTRODUÇÃO}

O vírus da diarreia viral bovina (BVDV) pertence ao gênero Pestivirus da família Flaviviridae e é uma das principais causas de perdas econômicas na bovinocultura. A transmissão de BVDV por contato direto é a mais importante, porém a transmissão indireta também já foi observada. Produtos injetáveis contaminados, roupas e instrumentos veterinários ou o ser humano podem disseminar BVDV não somente dentro do rebanho, mas também entre rebanhos $[5,10]$. Sob condições experimentais, moscas hematófagas já foram capazes de transmitir mecanicamente o vírus a bovinos [16], porém a transmissão de BVDV por vetores artrópodes em condições naturais nunca foi descrita.

Por outro lado, as zonas de clima tropical e subtropical são caracterizadas por abundância de artrópodes hematófagos que estão continuamente alimentando-se em bovinos. No Brasil, o mais importante deles é o carrapato Rhipicephalus (Boophilus) microplus [11].

Os vírus transmitidos por carrapatos são menos estudados do que aqueles transmitidos por insetos, mas já foram isolados em $R$. microplus vírus pertencentes às famílias Orthomyxoviridae, Reoviridae e Bunyaviridae [6]. Mais recentemente, o vírus da febre aftosa foi identificado e isolado em $R$. pulchellus [15]. Como o BVDV está amplamente disseminado nas criações de bovinos do Brasil e não existem trabalhos relacionados à transmissão viral pelo carrapato $R$. microplus, o objetivo deste trabalho foi investigar a possibilidade de transmissão do BVDV por carrapatos $R$. microplus sob condições experimentais.

\section{MATERIAIS E MÉTODOS}

\section{Animais e desenho experimental}

No presente trabalho, foram utilizados três bovinos (Bos taurus taurus) machos clinicamente saudáveis, com 20 meses de idade. Os animais foram mantidos estabulados individualmente, com livre acesso a comida e água, tratados conforme recomendações do Colégio Brasileiro de Experimentação Animal (COBEA). Um destes animais era PI e foi utilizado como fonte de BVDV neste trabalho. O PI era da raça Aberdeen Angus e foi previamente identificado no teste de triagem de bezerros de um rebanho de gado de corte com surto de BVDV no verão de 2007 e 2008. Este animal apresentava menor desenvolvimento do que seus contemporâneos e as análises laboratoriais de imunoistoquímica de corte de pele e teste de Transcrição Reversa seguida de Reação em Cadeia da Polimerase (RT-PCR) foram positivos para BVDV. Nova análise de RT-PCR, realizada 60 dias após os primeiros testes, identificou permanência de viremia e os testes sorológicos deste animal confirmaram ausência de anticorpos contra BVDV (dados não mostrados). Este PI foi infestado com 20.000 larvas de R. microplus da cepa Porto Alegre (livre de patógenos) com 10 dias de idade. Ao fim do ciclo de vida parasitária (aproximadamente três semanas), as fêmeas totalmente ingurgitadas (teleóginas) que espontaneamente se desprenderam do bovino e caíram no piso da baia foram coletadas, lavadas e acondicionadas em placas de Petry, sendo mantidas entre $25-28^{\circ} \mathrm{C}$ e $80 \%$ de umidade relativa até o término da postura dos ovos. Os ovos foram acondicionados em tubos de ensaio, pesados e mantidos nas mesmas condições das fêmeas em postura para possibilitar a eclosão das larvas.

As larvas de 10 dias de idade, oriundas da progênie das teleóginas que ingurgitaram no bovino PI foram utilizadas para infestar um segundo bovino (374), raça Hereford. Um terceiro bovino (373) da mesma raça foi infestado com larvas da mesma cepa de $R$. microplus oriundas de teleóginas ingurgitadas em um bovino não PI e foram utilizadas como controles negativos.

Foram coletadas amostras de sangue dos bovinos infestados nos dias zero, seis, 13 e 21 após infestação, os soros foram separados e estocados à $-80^{\circ} \mathrm{C}$ até as análises. Amostras de teleóginas ingurgitadas nos bovinos acima citados, além de sua progênie de ovos e larvas, também foram coletadas e estocadas em nitrogênio líquido para extração de RNA.

\section{Extração de RNA}

A extração do RNA total das amostras de soros e carrapatos foi realizada utilizando Trizol ${ }^{\circledR} \mathrm{LS}^{1}$ seguindo as recomendações do fabricante. Para tanto, foram utilizados $250 \mu \mathrm{L}$ dos soros dos bovinos acima referidos. As amostras de carrapatos foram submetidas a uma preparação prévia que consistiu de maceração em gral e pistilo do material mantido congelado em nitrogênio líquido. Uma pequena quantidade do macerado, equivalente ao volume de 
$50 \mu \mathrm{L}$ de amostra, foi colocado em tubo de reação com $750 \mu \mathrm{L}$ de $\mathrm{TRIzol}^{\circledR} \mathrm{LS}$ e foi adicionada água ultrapura para completar o volume total de $1000 \mu \mathrm{L}$. O RNA precipitado foi ressuspendido em $50 \mu \mathrm{L}$ de água ultrapura.

\section{Transcrição reversa seguida de reação em cadeia da polimerase (RT-PCR)}

As reações de RT-PCR para amplificação da região 5 ' não traduzida de genoma viral foram realizadas utilizando os iniciadores 324 e 326 [18] e kit comercial "Superscript ${ }^{\circledR}$ One Step RT-PCR with Platinum ${ }^{\circledR}$ Taq" ${ }^{2}$. Para tanto, as reações foram preparadas em um volume total de $25 \mu \mathrm{l}$ contendo $2 \mu \mathrm{L}$ de RNA total da amostra, 40 pmol de cada iniciador e demais soluções do kit, conforme recomendações do fabricante. A síntese de DNA complementar foi realizada a $50^{\circ} \mathrm{C}$ por $30 \mathrm{~min}$. As condições da PCR foram uma desnaturação inicial de $95^{\circ} \mathrm{C}$ por 3 min seguida de 35 ciclos de desnaturação a $95^{\circ} \mathrm{C}$ por $1 \mathrm{~min}$, anelamento a $56^{\circ} \mathrm{C}$ por 1 min e extensão a $72^{\circ} \mathrm{C}$ por 1 min, realizadas em um termociclador automático modelo "Veriti ${ }^{\circledR 96-w e l l " 3 . ~ N a ~ e t a p a ~ s e g u i n t e, ~ o s ~ p r o-~}$ dutos de amplificação foram submetidos à eletroforese em gel de agarose 2,0\% com $0,1 \mu \mathrm{g} / \mathrm{mL}$ de "blue green loading dye I"4, em tampão de tris-ácido acético-EDTA [14] para detectar o produto de amplificação com 288 pares de bases.

\section{RESULTADOS}

\section{Infecção experimental de bovino}

Nenhum sinal clínico da infecção do BVDV foi detectado no bovino 374 após a infestação com larvas da progênie dos carrapatos expostos ao bovino PI, ou no bovino 373, infestado com as larvas da progênie de carrapatos não expostos ao vírus.

\section{Detecção de RNA viral em soros de bovinos}

Os resultados da RT-PCR para amplificação de um fragmento do genoma do BVDV a partir das amostras do bovino 374, infestado com larvas da progênie de carrapatos expostos ao BVDV, e do bovino 373, infestado com carrapatos não expostos ao vírus, foram negativos. Quando a amostra de RNA extraído do soro obtido do bovino PI foi submetida à RT-PCR, observou-se amplicons com aproximadamente 288 pares de bases, indicativo da presença de RNA viral.

\section{Detecção de RNA viral em carrapatos}

Foi possível detectar RNA viral no teste de RT-PCR realizado a partir da extração de RNA total do grupo das fêmeas totalmente ingurgitadas desprendidas do bovino PI (Figura 1). As amostras da progênie, ovos e larvas, destes carrapatos alimentados no bovino PI foram negativas na análise por RT-PCR para BVDV (Figura 1). Como esperado, as amostras dos grupos das teleóginas alimentados em bovino negativo para BVDV, bem como de seus ovos e larvas, foram negativas na RT-PCR.

\section{DISCUSSÃO}

No presente trabalho, a detecção de RNA viral em teleóginas que completaram seu ciclo parasitário após repasto no bovino PI confirmou a possibilidade de infecção das fêmeas de carrapatos alimentados em animais persistentemente infectados por BVDV. Os resultados também sugerem que não há transmissão transovariana, visto que a progênie destes carrapatos foi negativa na RT-PCR e não foi capaz de transmitir o vírus a um bovino negativo.

O ponto central da epidemiologia do BVDV é a infecção persistente. O animal precocemente infectado via transplacentária apresenta uma viremia $\left(10^{5} \mathrm{CCID}_{50} / \mathrm{mL}\right.$ de sangue) persistente por longos períodos ou toda vida e é a principal fonte de contaminação para bovinos susceptíveis [3,7]. No Brasil, BVDV está amplamente distribuído nas criações de bovinos e estudos de prevalência estimaram uma

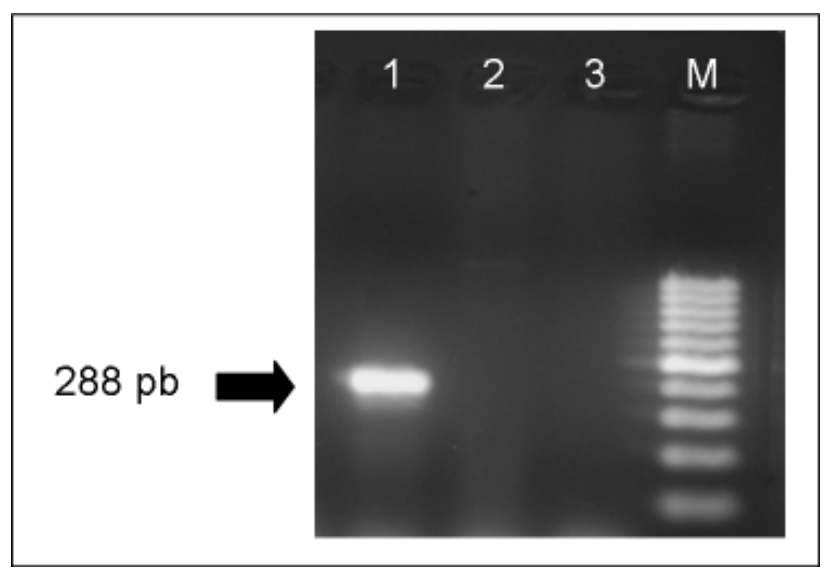

Figura 1. Eletroforese em gel de agarose $2 \%$ dos produtos de amplificação da RT-PCR da região 5' não traduzida do genoma viral de BVDV. Posição M corresponde a padrões de marcador molecular com escala de 100 pares de bases. Posições 1 à 3 correspondem as amostras de teleóginas, ovos e larvas de carrapato $R$. microplus. 
infecção de rebanho de $90 \%$ e $82 \%$, respectivamente $[12,17]$.

Os artrópodes hematófagos são considerados vetores mecânicos na transmissão indireta de BVDV, mas o papel dos carrapatos ainda não havia sido investigado [16]. Campanhas de controle e erradicação de BVDV em curso em zonas de clima temperado consideram não existir risco de transmissão por vetores artrópodes e não recomendam nenhuma medida de controle específica [7]. O carrapato bovino é o ectoparasito mais importante de animais domésticos da América Latina. O R. microplus causa grandes prejuízos à produção animal, através de danos diretos, como anemia, e indiretos via transmissão dos agentes do complexo tristeza parasitária bovina, Babesia spp. e Anaplasma marginale [4]. Contudo, seu papel na transmissão de agentes virais, particularmente do BVDV, não havia sido estudado. Vale ressaltar que, até hoje, o risco de contágio de BVDV relacionado a carrapatos resume-se a utilização de animais PI como doadores de sangue destinado à premunição de bovinos sem contato prévio com o carrapato ou aos patógenos a ele associados [2].

Taxonomicamente, arbovírus ("arthropodborne viruses") são um grupo heterogêneo de vírus de vertebrados unificados por uma única característica ecológica, transmissão por artrópodes hematófagos nos quais eles replicam. Este grande grupo é formado por vírus de várias famílias, principalmente de vírus RNA. O gênero Flavivirus, da família Flaviviridae, é composto por muitos arbovírus responsáveis por importantes doenças infecciosas em todo o mundo, como dengue, febre amarela e doença da febre do Nilo ocidental. Arbovírus transmitidos por carrapatos são menos estudados do que aqueles transmitidos por insetos, mas sabe-se que a principal rota de transmissão viral por carrapatos infectados é através da saliva secretada durante o repasto sanguíneo $[6,9]$. Interessantemente, um estudo de prospecção de arbovírus em carrapatos coletados de bovinos domésticos em abatedouro de Nairobi, Quênia, identificou o vírus da febre aftosa (FMDV). Apesar de não ser considerado um arbovírus, o FMDV foi identificado e isolado de $R$. pulchellus. Este trabalho demonstrou o potencial risco de transmissão de vírus, sejam eles arbovírus ou não, por várias espécies de carrapatos em bovinos, inclusive os pertencentes ao gênero Rhipicephalus [15].
Visto que o $R$. microplus é um ectoparasito monoxeno, a infecção de fêmeas adultas alimentadas em um bovino positivo para BVDV não representaria risco direto de transmissão para outros bovinos. Contudo, a infestação por $R$. microplus poderia estar relacionada à disseminação de BVDV no rebanho através de transmissão transovariana dos carrapatos para sua progênie [6]. Além disso, é importante ressaltar que o macho de $R$. microplus, diferentemente das fêmeas, realiza um processo de hematofagia não contínuo e pode transitar, à procura de fêmeas não fecundadas, entre diferentes bovinos ao longo de sua vida, parasitando diferentes indivíduos [8]. Assim sendo, este fato não permite excluir a presença de um risco direto de transmissão de agentes virais no rebanho por um mesmo espécime de $R$. microplus [13]. De fato, em condições de contato íntimo entre os animais de um rebanho, além dos machos adultos, formas larvais de $R$. microplus podem trocar de hospedeiro nos estágios iniciais de seu ciclo de vida [8]. Além disso, a presença do vírus no interior das teleóginas representa um reservatório de presença BVDV no ambiente, que pode constituir-se em uma fonte de contaminação oral dos bovinos, como diversos outros fômites contaminados. Por sua vez, experiências de campo têm demonstrado que a alta densidade animal e condições de criação intensiva favorecem a rápida disseminação de BVDV em rebanhos bovinos [1,5]. Também é possível que a presença de carrapatos possa ser um fator adicional a ser considerado na transmissão do BVDV. De fato, experimentos estão em andamento para verificar a viabilidade e infectividade do BVDV no interior das teleóginas, bem como para investigar a infecção de machos de $R$. microplus expostos ao BVDV.

\section{CONCLUSÃO}

O presente trabalho demonstrou a possibilidade de infecção do carrapato bovino $R$. microplus por repasto sanguíneo em animais PI por BVDV, confirmando a importância do estudo de vetores hematófagos na epidemiologia de agentes virais de animais domésticos.

Como a transmissão via transovariana não foi confirmada, o papel do carrapato bovino na transmissão do BVDV em condições naturais continua incerto. 
Almeida L.L., Marks F.S., Junior J.R., Santos A.S., Gomes D.C., Junior I.S.V., Driemeier D. \& Canal C.W. 2010. Detecção do vírus da diarreia viral bovina em carrapatos Rhipicephalus (Boophilus)...

Acta Scientiae Veterinariae. 38(2): 155-159.

\section{NOTAS INFORMATIVAS}

${ }^{1}$ Trizol ${ }^{\circledR}$ LS Reagent, Invitrogen, Carlsbad, Estados Unidos. ${ }^{2}$ Superscript ${ }^{\circledR}$ One Step RT-PCR with Platinum ${ }^{\circledR}$ Taq, Invitrogen, Carlsbad, Estados Unidos.
${ }^{3}$ Veriti ${ }^{\circledR} 96-$ well Thermal Cycler, Applied Biosystems, Foster City, Estados Unidos.

${ }^{4}$ Blue green loading dye I, LGC Biotecnologia, São Paulo, Brasil.

\section{REFERÊNCIAS}

1 Arenhart S., Bauermann F.V., Oliveira S.A.M., Weiblen R. \& Flores E.F. 2009. Excreção e transmissão do vírus da diarreia viral bovina por bezerros persistentemente infectados. Pesquisa Veterinária Brasileira. 29 (9): 736-742.

2 Bock R.E, Rodwell B.J. \& McCowan M. 1997. Detection of calves persistently infected with bovine pestivirus in a sample of dairy calves in south-eastern Queensland. Australian Veterinary Journal. 75 (9): 656- 659.

3 Brock K.V., Grooms D.L., Ridpath J. \& Bolin S.R. 1998. Changes in levels of viremia in cattle persistently infected with bovine viral diarrhea virus. Journal of Veterinary Diagnostic Investigation. 10: 22-26.

4 Gonzáles J.C. 2003. O Controle do Carrapato do Boi. 3.ed. Passo Fundo: Universidade de Passo Fundo, 128p.

5 Houe H. 1999. Epidemiological features and economical importance of bovine virus diarrhoea virus (BVDV) infections. Veterinary Microbiology. 64: 89-107.

6 Labuda M. \& Nuttall P.A. 2004. Tick-borne viruses. Parasitology. 129: 221-245.

7 Lindberg A.L.E. \& Alenius S. 1999. Principles for eradication of bovine viral diarrhoea virus (BVDV) infections in cattle populations. Veterinary Microbiology. 64: 197-222.

8 Mason C.A. \& Norval R.A.I. 1981. The transfer of Boophilus microplus (Acarina: Ixodidae) from infested to uninfested cattle under field conditions. Veterinary Parasitology. 8 (2): 185-188.

9 Murphy F.A., Gibbs E.P., Horzinek M.C. \& Studdert M.J. 1999. Veterinary Virology 3nd. edn. San Diego: Academic Press, Elsevier, 629p.

10 Niskanen R. \& Lindberg A. 2003. Transmission of bovine viral diarrhoea virus by unhygienic vaccination procedures, ambient air, and from contaminated pens. The Veterinary Journal, 165: 125-130.

11 Parizi L.F., Pohl P.C., Masuda A., Da Silva Vaz I., 2009. New approaches toward anti-Rhipicephalus (Boophilus) microplus tick vaccine. Brazilian Journal of Veterinary Parasitology 18 (1): 1-7.

12 Quincozes C.G., Fischer G., Hübner S.O., Vargas G.D., Vidor T. \& Brod C.S. 2007. Prevalência e fatores associados à infecção pelo vírus da diarreia viral bovina na região Sul do Rio Grande do Sul. Semina: Ciências Agrárias. 28 (2): 269276.

13 Romero C.H., Abaracon D., Rowe C.A. \& Silva A.G. 1984. Bovine leukosis virus infectivity in Boophilus microplus ticks. The Veterinary Record. 115 (17): 440-441.

14 Sambrook J., Fritsch E. \& Maniatis T. 1989. Agarose gel electrophoresis. In: Molecular cloning: A Laboratory Manual. 2nd. edn. New York: Cold Spring Harbor Laboratory, pp.6.3-6.13.

15 Sang R., Onyango C., Gachoya J., Mabinda E., Konongoi S., Ofula V., Dunster L., Okoth F., Coldren R., Tesh R., Rosa A.T., Finkbeiner S., Wang D., Crabtree M. \& Miller B. 2006. Tickborne arbovirus surveillance in market livestock, Nairobi, Kenya. Emerging Infectious Diseases. 12 (7): 1074-1080.

16 Tarry D.W.; Bernal L. \& Edwards S. 1991. Transmission of bovine virus diarrhoea virus by blood feeding flies. The Veterinary Record. 128: 82-84.

17 Thompson J.A., Leite R.M.H., Gonçalves V.S.P., Leite R.C., Bandeira D.A., Herrmann G.P., Moreira E.C., Prado P.E.F., Lobato Z.I.P., Brito C.P.T. \& Lage A.P. 2006. Spatial hierarchical variances and age covariances for seroprevalence to Leptospira interrogans serovar hardjo, BoHV-1 and BVDV for cattle in the State of Paraíba, Brazil. Preventive Veterinary Medicine. 76: 290-301.

18 Vilcek S., Herring A.J., Herring J.A., Nettleton P.F., Lowings J.P. \& Paton D.J. 1994. Pestiviruses isolated from pigs, cattle and sheep can be allocated into at least three genogroups using polymerase chain reaction and restriction endonuclease analysis. Archives of Virology. 136: 309-323.

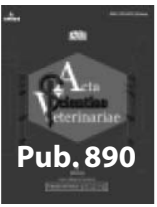


